\title{
Thermal tolerance of Strongylocentrotus purpuratus early life history stages: mortality, stress-induced gene expression and biogeographic patterns
}

\author{
LaTisha M. Hammond • Gretchen E. Hofmann
}

Received: 11 December 2009/Accepted: 1 August 2010/Published online: 28 August 2010

(C) The Author(s) 2010. This article is published with open access at Springerlink.com

\begin{abstract}
In this study, we examined the differential thermal tolerance of Strongylocentrotus purpuratus early life history stages by comparing high temperature-induced mortality and the relative levels of the stress-induced gene, hsp 70 , between $S$. purpuratus embryos and larvae from adults collected throughout the species range. There was no significant difference between gastrulae and 4-arm plutei mortality from all sites examined. Furthermore, there was little variability in temperature tolerance across the biogeographic range as southern gastrulae and 4-arm plutei exhibited similar tolerances to northern individuals. Relative levels of $h s p 70$ mRNA expression did not differ overall between the two developmental stages at each site. Across sites, all gastrulae and 4-arm plutei exhibited maximum $h s p 70$ expression at approximately $25^{\circ} \mathrm{C}$; however, the range of $h s p 70$ expression was narrower in southern individuals, suggesting they are living closer to their upper thermal limit than northern individuals.
\end{abstract}

\section{Introduction}

In marine ecosystems, temperature is known to set species' distribution limits, creating distribution boundaries on scales that range from the biogeographic (Brown et al. 1996; Pörtner 2002; Sagarin and Gaines 2002) to small scale (Helmuth and Hofmann 2001; Miller et al. 2009). For benthic invertebrates, the effects of temperature have been

Communicated by S. Uthicke.

L. M. Hammond $(\bowtie) \cdot$ G. E. Hofmann

Department of Ecology, Evolution and Marine Biology,

University of California, Santa Barbara, CA 93106-9620, USA

e-mail: hammond@lifesci.ucsb.edu studied extensively in adult forms (e.g., Stillman 2003; Somero 2005; Stillman and Tagmount 2009). Studies on earlier life history stages have often characterized them as being more vulnerable to environmental stress such as temperature and UV exposure (Adams and Shick 2001; Edmunds et al. 2001; but see Hamdoun and Epel 2007). Given that climate change models predict changes in the abiotic characteristics of oceans (IPCC 2007; Doney et al. 2009), understanding physiological tolerances of larval forms is particularly important. In addition, while oceanographic processes such as current patterns and upwelling often dictate species range boundaries for organisms with planktonic larvae (Gaylord and Gaines 2000; deRivera et al. 2007), physiological temperature tolerances of the larvae, in conjunction with oceanographic processes, strongly influence the adult biogeography (Zacherl et al. 2003; Sanford et al. 2006).

With its broad biogeographic range, extending from southern Alaska to central Baja California, Mexico, the purple sea urchin Strongylocentrotus purpuratus as a species experiences a wide range of environmental temperatures, ranging from 4 to $20^{\circ} \mathrm{C}$ (Morris et al. 1980) on average, with the potential to experience higher temperatures in shallow intertidal tide pools. S. purpuratus urchins have pelagic, free-swimming larvae that remain in the water column for an average of 29-86 days, depending on the latitude and water temperature (Strathmann 1978; Strathmann 1987). After this planktonic larval duration, the larvae metamorphose and settle to become benthic juveniles. It is during the pelagic duration that embryos and larvae are exposed to variable temperature conditions, moving with and potentially through water masses of different temperatures, while also experiencing daily temperature fluctuations in the surface waters. Within larval ecology, the relationship between temperature and 
larval performance has been studied extensively at the whole-organism level. Many studies have investigated the relationship between seawater temperature and larval development, correlating warmer temperatures with faster development times (Fujisawa 1989; Fujisawa and Shigei 1990; Sewell and Young 1999; Staver and Strathmann 2002). There are limits, however, when temperatures exceed physiological capabilities, and embryos and larvae are no longer able to develop and function at these extreme temperatures (Sewell and Young 1999). For example, in $S$. purpuratus specifically, Farmanfarmaian and Giese (1963) noted that embryonic offspring of central Californian adults developed normally between 13 and $20^{\circ} \mathrm{C}$; however, eggs fertilized between 5 and $13^{\circ} \mathrm{C}$ and above $20^{\circ} \mathrm{C}$ developed abnormally and exposure to $25^{\circ} \mathrm{C}$ led to mortality shortly after exposure. As embryos and larvae approach these limits of their temperature tolerances, they exhibit a number of responses at both the molecular and whole-organism levels as a result of these temperature extremes.

At the whole-organism level in marine ectotherms, oxygen consumption, heart rate, and mortality are some of the measures that have been used as indices for thermal stress (Stillman and Somero 2000; Pörtner 2002; Stillman 2003). These indices of thermal stress, alongside molecular responses, have been widely studied in adults. The focus more recently has been on relating adult physiological performance to biogeography (Sorte and Hofmann 2004; Osovitz and Hofmann 2005; Somero 2005; see Gaston et al. 2009; Stillman and Tagmount 2009) as macrophysiological studies will provide further insight into how organisms will respond to long-term environmental changes such as climate change (Chown and Gaston 2008). Some larval studies have also explored whole-organism level thermal tolerances and development in relationship to adult habitat and biogeography (Johnson and Babcock 1994; Bingham et al. 1997). Investigating whole-organism level thermal indices, such as mortality, in early life history stages will provide more thorough profiles of marine ectotherm stress responses during their life cycles.

Larvae employ a number of molecular mechanisms to handle thermal stress. One mechanism involved in thermal tolerance is the heat-shock response (HSR). The HSR is a molecular-level gene activation event in response to physiological stresses such as high temperatures (Lindquist 1986) and is induced under thermally stressful conditions in marine organisms (Tomanek and Somero 1999; Hofmann 2005) and terrestrial invertebrates (Lindquist 1986; Krebs and Feder 1998; Goto and Kimura 1998). Of the genes that are activated during the HSR, the inducible form of $h s p 70$ is one that has been used extensively to quantify the HSR. $h s p 70$ is a $70 \mathrm{kD}$ family of genes that codes for heat-shock proteins (hsps), molecular chaperones that aide in the refolding or translocation of denatured proteins allowing the cell to maintain proper functions (Lindquist 1986; Morimoto 1998). Many studies have focused their attention on inducible $h s p 70$ in adult organisms; however, fewer studies have been carried out with early developmental stages.

It is important to note that early embryos and larvae go through a vast number of cellular and morphological changes, often over a relatively short time ( $S$. purpuratus spend just a few days transitioning from fertilized egg to pluteus larvae), potentially leaving them differentially susceptible to stress as much of their energy may be allocated to cellular divisions and rearrangements (Krebs and Feder 1998; Morimoto 1998; Hamdoun and Epel 2007). Furthermore, they may respond or manifest defense mechanisms at different capacities. Studies have found that before the gastrula stage, embryos of the Mediterranean sea urchin Paracentrotus lividus exposed to high temperatures produced $h s p 70$ transcript but at such low concentrations it was almost undetectable, and there was no discernable HSR compared to the larvae (Sconzo et al. 1986; Sconzo et al. 1995; Giudice et al. 1999). Similar results were found by Brown et al. (2004) in Ostreola conchaphila oyster embryos and larvae: pre-gastrula embryos lacked a measurable HSR. The absence of a measurable HSR is not surprising as, generally, embryos do not begin to transcribe their genome until they have reached the mid-blastula or gastrula stage (Wolpert 1992; Leptin 2005), transcription that includes inducible hsps. Therefore, we focused on gastrulae as the first stage of interest for this study. As it is one of the earliest points at which $h s p 70$ is expressed in measurable amounts (Sconzo et al. 1986; Sconzo et al. 1995; Giudice et al. 1999), gastrulae may regulate the response differently than older larvae, necessitating an embryo to larva comparison.

In the present study, we examined thermal tolerance of $S$. purpuratus larvae using two biological measures. At the whole-organism level, embryos and larvae were exposed to a gradient of increasing temperatures and mortality was assessed. At the molecular level, $h s p 70$ mRNA transcript was measured as it is a biological indicator of thermal stress. These two metrics were used to compare $S$. purpuratus at the gastrula and 4-arm pluteus stages to assess developmental differences in thermal tolerance and $h s p 70$ expression of embryos and larvae spawned from adults collected from locations across the range of $S$. purpuratus. Because the range of $S$. purpuratus is relatively large, with a potential $10-15^{\circ} \mathrm{C}$ difference in the temperature at which oogenesis occurs in nature between the range boundaries (National Data Buoy Center at NOAA; http://www.ndbc. noaa.gov/), embryos and larvae of adults from different thermal regimes may respond differently to thermal stress. Therefore, investigations of thermal tolerance of progeny 
from different latitudes may elucidate the relationship between larval physiological tolerances and biogeography.

\section{Methods}

Urchin collection and larval culturing

Approximately 20 S. purpuratus urchins were collected from 4 sites along the west coast of North America between Oregon and Baja California, Mexico: Fogarty Creek, OR (FC; $44^{\circ} 51^{\prime} \mathrm{N}, 124^{\circ} 00^{\prime} \mathrm{W}$ ), Santa Cruz, CA (SC; $36^{\circ} 53^{\prime} \mathrm{N}, 122^{\circ} 04^{\prime} \mathrm{W}$ ), Santa Barbara, CA (SB; $34^{\circ} 14^{\prime} \mathrm{N}$, $119^{\circ} 53^{\prime} \mathrm{W}$ ), and Eréndira, Baja California, Mexico (ER; $31^{\circ} 16^{\prime} \mathrm{N} 116^{\circ} 23^{\prime} \mathrm{W}$; Fig. 1). The monthly average temperatures range from 10 to $14^{\circ} \mathrm{C}$ in central Oregon, $12-15^{\circ} \mathrm{C}$ near Santa Cruz, $13-17^{\circ} \mathrm{C}$ in Santa Barbara, and $15-21^{\circ} \mathrm{C}$ near Eréndira (FC, SC and SB data: National Data Buoy Center at NOAA; http://www.ndbc.noaa.gov; ER: LluchCota et al. 2000). The urchins were collected from the subtidal or very low intertidal zone during the height of the $S$. purpuratus spawning season relative to each site (ER: January; SB: February; SC: March; FC: late March-early April). Urchins were brought back to the University of California, Santa Barbara and placed in flow-through tanks set to the temperatures at which they were collected (FC: $\sim 10^{\circ} \mathrm{C}$; SC: $12-13^{\circ} \mathrm{C}$; SB: $\sim 15^{\circ} \mathrm{C}$; ER: $\sim 15^{\circ} \mathrm{C}$ ). Urchins were held for approximately 1-4 days prior to spawning. From each sample site, 3 to 4 pairs of one male and one female were spawned, and each pair was handled separately. Urchins were shaken to induce spawning. If shaking was not sufficient, urchins were injected with $\sim 0.5-1.0 \mathrm{~mL}$ of $0.5 \mathrm{M} \mathrm{KCl}$. Females were inverted over beakers of $0.22-0.35 \mu \mathrm{m}$ filtered sea water (FSW) into which they shed their eggs. Males were dry spawned. The sperm were removed, placed into microcentrifuge tubes, and kept cold on ice for no more than 15 min until fertilization. Eggs were fertilized with a sperm concentration of $\sim 20 \mu \mathrm{L}$ per $100 \mu \mathrm{L}$ of eggs in a 1-L beaker of FSW. Fertilization success was checked within 5 min of sperm addition and only eggs with a success rate of $90 \%$ or greater were used. After fertilization, zygotes from each separate pair were washed with FSW to remove excess sperm, and each group zygotes were divided equally into 4-, 3-L culture containers at an average density of 500,000 eggs per culture. Embryos and larvae were raised at the temperatures at which the adults were collected relative to each site. Each culture was gently stirred by paddles as described in Strathmann 1987. Culture water was changed once every $24 \mathrm{~h}$, any dead embryos or larvae were removed, and once late prism stage was reached ( $\sim 45-75 \mathrm{~h}$ post-fertilization, depending on the seawater temperature), they were fed a mixed diet of algae (Reed-

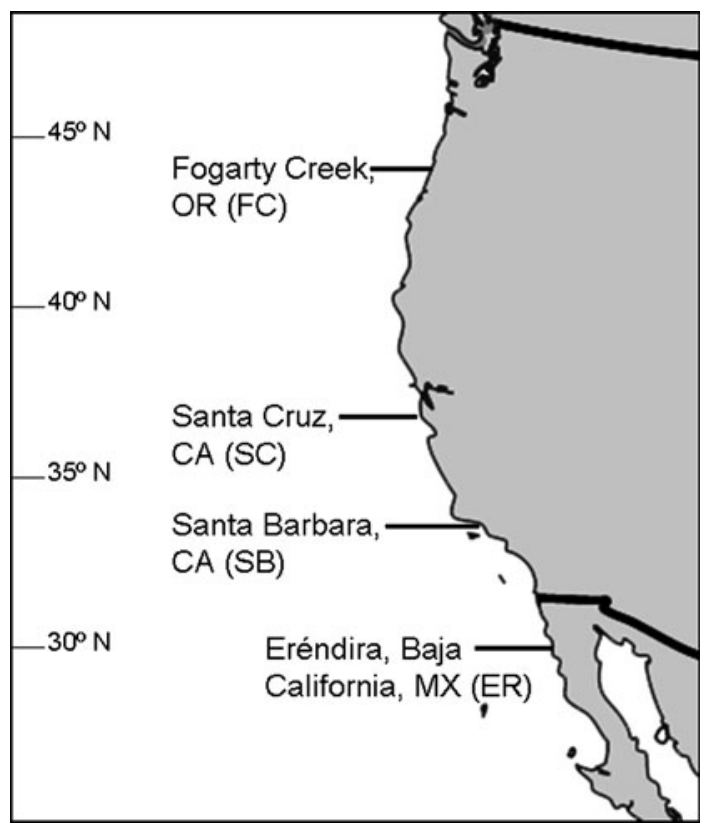

Fig. 1 Strongylocentrotus purpuratus collection sites: Fogarty Creek, OR (FC), Santa Cruz, CA (SC), Santa Barbara, CA (SB), Eréndira, Baja California, MX (ER)

Mariculture; Instant Algae Shellfish Diet 1800: Isochyrsis, Pavlova, Tetraselmis, and Thalassiosira weissflogii at $\sim 2$ billion cells $\mathrm{mL}^{-1}$ ) once before being sampled at the 4 -arm pluteus stage $(\sim 72-114 \mathrm{~h}$ p.f. depending on the seawater temperature).

\section{Larval sampling}

Once cultures reached the gastrula (36-70 h p.f. depending on rearing temperature) or 4-arm pluteus stage (72-114 p.f.), gastrulae and 4-arm plutei from each male-female pair were sampled from their respective cultures and divided into 33-, 20-mL scintillation vials. To do this, gastrulae or larvae from 2 of the 3-L culture containers were combined and mixed (the remaining 2 culture containers were combined, mixed, and then individuals were split into 4-, 3-L cultures to reduce the density for the developing gastrulae that would later be sampled for 4-arm plutei). From this larger stock, 33 samples of either 26,000-32,000 gastrulae or 4,000-5,000 4-arm plutei were measured out volumetrically and concentrated down to $1 \mathrm{~mL}$ for each of the 33 vials. The concentrated $1 \mathrm{~mL}$ of either gastrulae or larvae was added to a $20-\mathrm{mL}$ scintillation vial that contained $9 \mathrm{~mL}$ of FSW. The high densities in each scintillation vial were necessary to ensure enough material was available for the genomic analysis of $h s p 70$ mRNA levels, a method that is not uncommon for attaining adequate levels of genomic material for heat-shock analysis (Bédard and Brandhorst 1986; Sconzo et al. 1995; Sconzo et al. 1997; Brown et al. 2004). 
Thermal tolerance trials

A temperature gradient heat block was used to conduct the thermal tolerance experiment. The gradient consisted of 11 rows of wells of different temperatures ranging from 10 to $32^{\circ} \mathrm{C}$ (Table 1). The following procedure was run separately for each of the 3-4 sets of fertilized eggs: three of the $20-\mathrm{mL}$ vials containing gastrulae or 4 -arm plutei were placed in each temperature row, representing replicates of temperature. The embryos or larvae remained at these temperatures for $1 \mathrm{~h}$, at which point they were removed and scored under a light microscope. To score, the embryos or larvae were mixed by gentle stirring and $1 \mathrm{~mL}$ was taken from each vial and, using a densitometer and light microscopy, one hundred larvae were counted to obtain percent mortality. Swimming larvae or larvae that exhibited cilia movement were scored as alive, and those with no cilia movement were scored as dead. In order to verify that $1 \mathrm{~h}$ was sufficient time for a thermal challenge and to ensure that embryos or larvae scored as dead after $1 \mathrm{~h}$ were actually dead, a subset of gastrulae and 4-arm plutei from SB adults were exposed to a 1-h heat shock at temperatures between 15 and $32^{\circ} \mathrm{C}$ as described in Table 1 , followed by recovery periods of $1,2,4$, and $26 \mathrm{~h}$. As mortality after each recovery period was not significantly different from the mortality observed immediately after the 1-h heat shock (data not shown), a 1-h heat shock was deemed sufficient for assessing mortality.

\section{Total RNA extraction}

After gastrulae and 4-arm plutei were counted for the mortality assessments, the FSW was filtered off for total RNA extraction. Each sample was homogenized in $500 \mu \mathrm{L}$ of TRIzol ${ }^{\circledR}$ Reagent (Invitrogen, Carlsbad CA, USA) and stored at $-80^{\circ} \mathrm{C}$ until the RNA was extracted. Total RNA was extracted following the TRIzol manufacturer's protocol with the following adjustments: After the initial TRIzol extraction, a second extraction using $100 \%$ chloroform was used. In addition to the precipitation of total RNA in the recommended volume of $100 \%$ isopropanol, a salt solution for precipitation (initial concentration: $1.2 \mathrm{M} \mathrm{NaCl}, 0.8 \mathrm{M}$ disodium citrate) of equal volume was used. The RNA was re-suspended in nuclease-free water, and their

Table 1 Temperatures of 1-h heat exposure $\left({ }^{\circ} \mathrm{C}\right)$ for each site

\begin{tabular}{ll}
\hline Site & Temperatures of 1-h heat exposure $\left({ }^{\circ} \mathrm{C}\right)$ \\
\hline FC & $10.5,13.0,15.0,17.2,19.3,21.1,23.1,25,26.9,28.8,30.8$ \\
SC & $13,15,16.8,18.3,20.1,21.1,23.7,25.4,27.2,29.1,31.0$ \\
SB & $15,16.9,18.7,20.3,21.8,23.4,25,26.7,28.4,30.1,31.9$ \\
ER & $15,16.9,18.7,20.3,21.8,23.4,25,26.7,28.4,30.1,31.9$ \\
\hline
\end{tabular}

concentrations were measured using a Nanodrop ${ }^{\circledR}$ ND1000 full-spectrum UV/vis spectrophotometer.

hsp70 analysis using qPCR

Once the concentrations of total RNA were determined, $100 \mathrm{ng}$ was reverse transcribed for cDNA synthesis using oligo dT and the ImProm-II ${ }^{\mathrm{TM}}$ Reverse Transcription System (Promega) following the manufacturer's protocol. Of the 11 heat-shock temperatures used in the thermal tolerance trials (Table 1), temperatures between 10 and $20^{\circ} \mathrm{C}$ were excluded for each site for $h s p 70$ analysis because no significant upregulation was anticipated between 10 and $20^{\circ} \mathrm{C}$ based on previous $h s p 70$ expression data in adult $S$. purpuratus (Osovitz and Hofmann 2005). Quantitative real-time PCR (qPCR) was used to determine the relative levels of $h s p 70$ mRNA following the method described in Osovitz and Hofmann (2005) with the following adjustments. Elongation factor $1-\alpha($ efl- $\alpha)$ was used as a control gene as its mRNA levels did not change significantly across temperature treatments. Primers for $e f l-\alpha$ and $h s p 70$ were designed using Bio-Rad Beacon designer software with the published $S$. purpuratus sequences for hsp70 (GenBank accession no. XR_026557.1) and efl- $\alpha$ (GenBank accession no. NM_001123497.1). Primers for hsp70 were as follows: $h s p 70$ sense- $5^{\prime}$-AAGATATGA GGTCCAACCCAAGAT-3'; anti-sense- $5^{\prime}$-TGCTGAAGCA CTGCTTGACA-3'. Primers for efl- $\alpha$ were as follows: efl- $\alpha$ sense- $5^{\prime}$-CAACGAAATCGTCAGGGAGGTC-3'; anti-sense- $5^{\prime}$-AGATTGGGATGAAGGGCACAG-3'. The concentration of the efl- $\alpha$ primer used was $0.5 \mu \mathrm{M}$. Briefly, quantitative real-time PCR was run in $20-\mu \mathrm{L}$ SYBR green supermix (Bio-Rad) reactions containing $2 \mu \mathrm{L}$ of template cDNA. The qPCRs were run with the following protocol: 1 cycle at $95^{\circ} \mathrm{C}$ for $3 \mathrm{~min}, 40$ cycles at $58^{\circ} \mathrm{C}$ for $10 \mathrm{~s}$ and $95^{\circ} \mathrm{C}$ for $1 \mathrm{~min}, 1$ cycle at $55^{\circ} \mathrm{C}$ for $1 \mathrm{~min}$. Relative mRNA levels were calculated as follows. $h s p 70$ and $e f 1-\alpha \mathrm{Ct}$ values (the value that represents the threshold cycle at which a threshold concentration of transcript is reached) were normalized to a single $S$. purpuratus larval standard run on every qPCR plate. The $h s p 70 \mathrm{Ct}$ values were then normalized to the corresponding efl- $\alpha$ values, resulting in the reported relative $h s p 70$ concentrations.

Statistical analysis

Statistical analyses were performed using JMP 7.0 (SAS). The $\mathrm{LT}_{50}$, the lethal exposure temperatures at which $50 \%$ of the embryos and larvae died, was used as a measure of mortality in the thermal tolerance trials. To determine the $\mathrm{LT}_{50}$, logistic regressions were calculated from the binary 
(alive or dead) mortality data from both gastrulae and 4-arm plutei at each site. For each developmental stage, the upper and lower $95 \%$ confidence intervals for the $\mathrm{LT}_{50} \mathrm{~S}$ were determined from the logistic regressions. Linear regressions were calculated within developmental stage to determine latitudinal trends in $\mathrm{LT}_{50}$ temperatures by fitting the $\mathrm{LT}_{50}$ data by latitude, and significant differences were indicated by non-overlapping 95\% confidence intervals. A Student's $t$-test was used to determine statistical significance between gastrulae and 4-arm plutei $\mathrm{LT}_{50} \mathrm{~s}$.

The hsp70 expression data were transformed using a Box-Cox transformation to meet the assumptions for a two-way ANOVA with temperature and developmental stage as factors with male-female pair nested within temperature. Tukey-Kramer Honestly Significant Difference tests were run for post hoc analysis to characterize the hsp70 induction profile and identify the thermal set-points for each developmental stage at each site.

\section{Results}

Thermal tolerance trials

The thermal tolerance range was determined by exposing embryos and larvae to a range of temperatures for $1 \mathrm{~h}$, and thermal tolerance was measured as percent mortality. Overall, embryos and larvae exhibited an abrupt threshold in mortality, regardless of the biogeography of the adults (Fig. 2). For all sites, mortality was consistently very low until the exposure temperature reached $29-30^{\circ} \mathrm{C}$, at which point mortality increased significantly and reached $100 \%$ mortality within $1-2^{\circ} \mathrm{C}$ of the initial increase (Fig. 2). Gastrulae and 4-arm plutei from FC and $\mathrm{SC}$ adults experienced $100 \%$ mortality at approximately $31^{\circ} \mathrm{C}$, while gastrulae and 4-arm plutei from SB and ER adults experienced $100 \%$ mortality at approximately $32^{\circ} \mathrm{C}$.

Given the sharp increase in mortality and the coarse resolution of mortality temperatures tested, the $\mathrm{LT}_{50} \mathrm{~S}$ were estimated from logistic regression curves. Accordingly, the $\mathrm{LT}_{50}$ temperatures for $\mathrm{FC}, \mathrm{SC}, \mathrm{SB}$, and $\mathrm{ER}$ gastrulae were $30.3,30.1,30.7$, and $30.9^{\circ} \mathrm{C}$, respectively (Table 2). The $\mathrm{LT}_{50}$ temperatures for $\mathrm{FC}, \mathrm{SC}, \mathrm{SB}$, and ER 4-arm plutei were $29.7,30.0,31.0$, and $31.0^{\circ} \mathrm{C}$, respectively (Table 2 ). There were no significant differences in mortality between gastrulae and 4-arm plutei for all sites (Student's $t$-test assuming unequal variances: $P=0.9121)$. A linear regression with $95 \%$ confidence intervals showed there was a relationship between $\mathrm{LT}_{50}$ and site for 4-arm plutei, although not significant $\left(r^{2}=0.7918, P=0.1101\right)$, and no relationship between $\mathrm{LT}_{50}$ temperature and site for gastrulae $\left(r^{2}=0.4692, P=0.315\right)$.

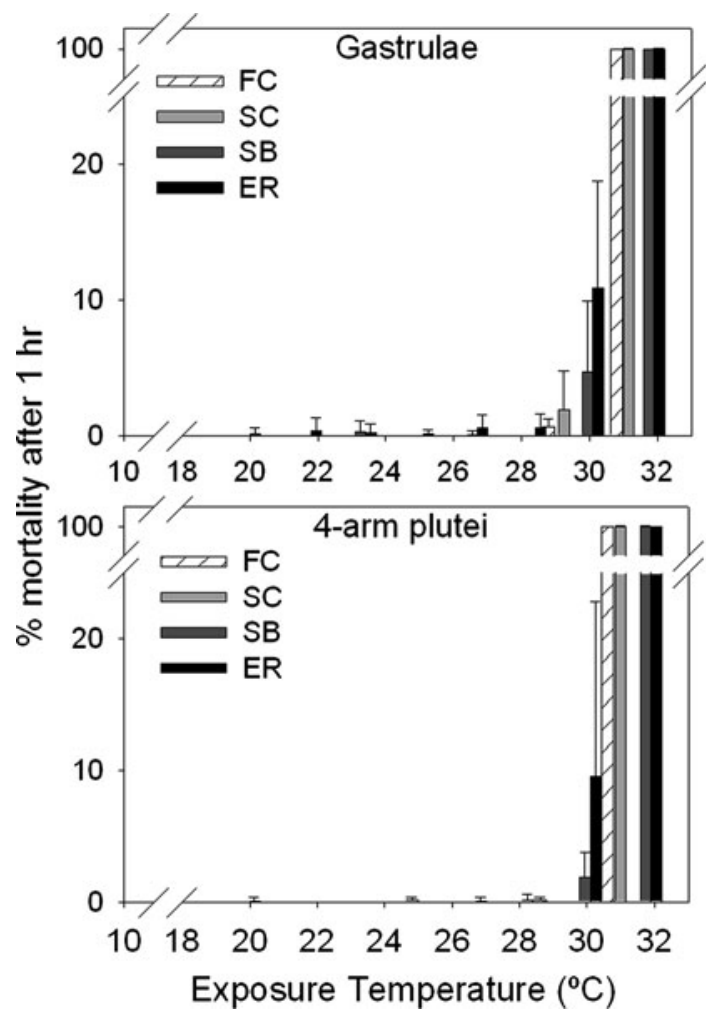

Fig. 2 Thermal tolerance plots showing percent mortality in $S$. purpuratus gastrulae and 4-arm plutei after 1-h heat shock from adults from FC (gastrulae, $n=2$; 4-arm plutei, $n=3$ where hereafter $n$ represents the number of male-female pairs spawned for each batch of embryos and larvae); SC (gastrulae, $n=3$; 4-arm plutei, $n=3$ ); $\mathrm{SB}$ (gastrulae, $n=3$; 4-arm plutei, $n=4$ ); and ER (gastrulae, $n=3$; 4-arm plutei, $n=4$ ). Error bars indicate standard error of malefemale pair replicates

Table $2 \mathrm{LT}_{50}$ temperatures $\left({ }^{\circ} \mathrm{C}\right)$ for $S$. purpuratus gastrulae and 4-arm plutei after a 1 -h heat exposure

\begin{tabular}{lllll}
\hline Stage & FC & SC & SB & ER \\
\hline Gastrulae & 30.3 & 30.1 & 30.7 & 30.9 \\
4-arm plutei & 29.7 & 30.0 & 31.0 & 31.0 \\
\hline
\end{tabular}

Expression of $h s p 70$ mRNA

The induction profile for $h s p 70$ mRNA expression was similar between developmental stages and at all four sites (Fig. 3). The overall two-way ANOVA results were significant for each site $(P<0.05)$ except SB $(P=0.1700)$. However, temperature had a highly significant effect in SB samples $(P=0.0007$; Table 3$)$. The discrepancy may be a result of the anomalously high expression at the control temperature from possible temperature stress during sample handling. The results from the two-way ANOVA for each site showed that temperature was the only significant effect (all $P<0.05$ ) except at SC where both temperature $(P<0.0001)$ and stage $(P=0.0218)$ were significant 
Fig. 3 Relative $h s p 70$ mRNA expression levels after 1-h heat shock in $S$. purpuratus gastrulae and 4-arm plutei of adults from FC (gastrulae, $n=2$; 4-arm plutei, $n=3$ ); SC (gastrulae, $n=3$; 4-arm plutei, $n=3$ ); SB (gastrulae, $n=3$; 4-arm plutei, $n=4$ ); and ER (gastrulae, $n=3$; 4-arm plutei, $n=4$ ). Values are relative to a common $S$. purpuratus larval standard and normalized to efl- $\alpha$. Error bars indicate standard error of male-female pair replicates
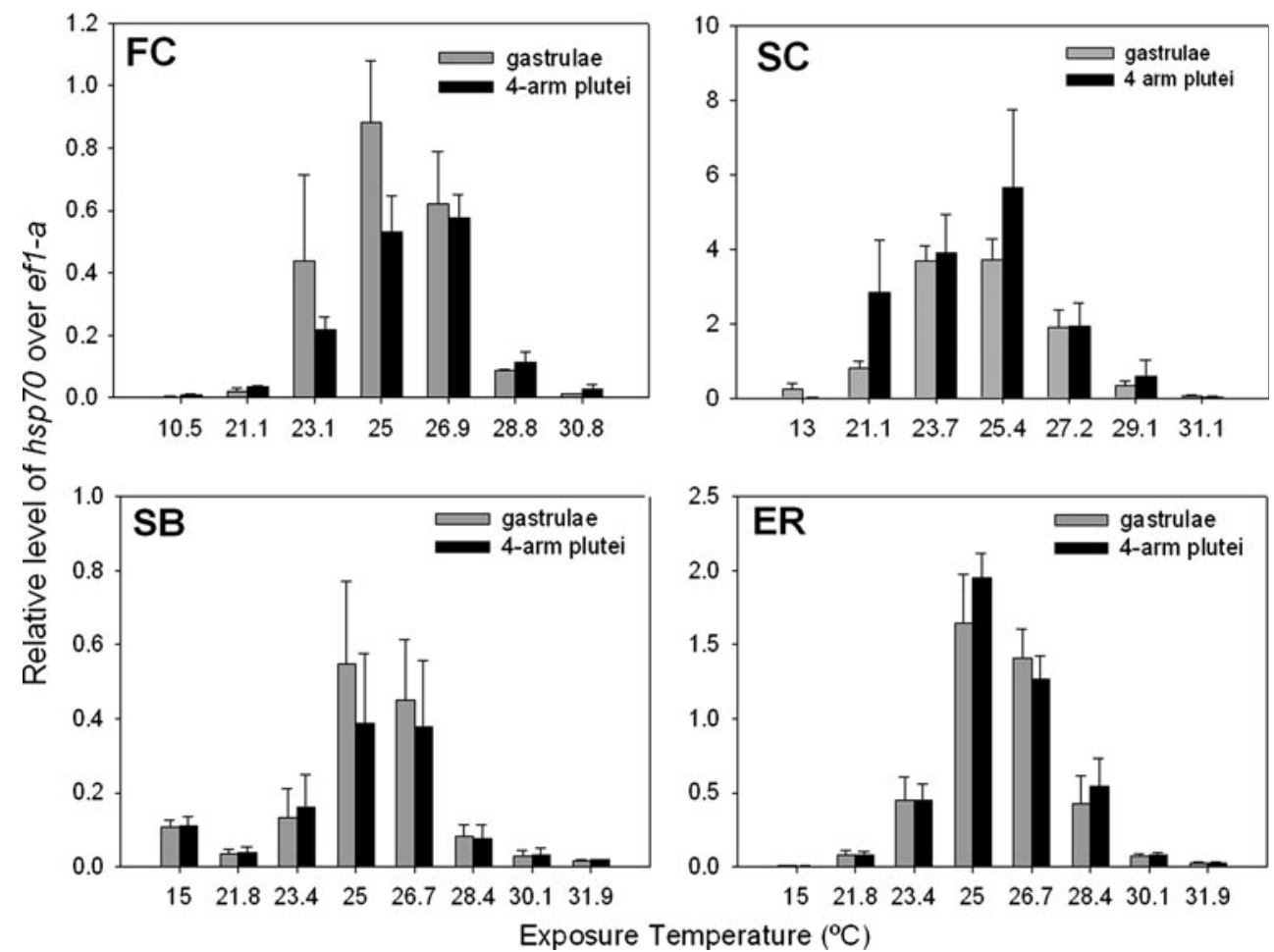

Table 3 Two-way ANOVA results testing for the effects of temperature and developmental stage on $h s p 70$ expression in $S$. purpuratus progeny from $\mathrm{FC}, \mathrm{SC}, \mathrm{SB}$, and $\mathrm{ER}$

\begin{tabular}{lrrc}
\hline & $d f$ & $F$ & $p$ \\
\hline FC & & & \\
Temperature & 6 & 41.5040 & $0.0001^{*}$ \\
Stage & 1 & 4.4644 & 0.0791 \\
Mate-pair[temperature] & 14 & 0.9890 & 0.5434 \\
Temperature $\times$ stage & 6 & 1.2608 & 0.3928 \\
SC & & & \\
Temperature & 6 & 23.4673 & $<0.0001^{*}$ \\
Stage & 1 & 6.7849 & $0.0218^{*}$ \\
Mate-pair[temperature] & 14 & 0.8158 & 0.6459 \\
Temperature $\times$ stage & 6 & 1.3802 & 0.2932 \\
SB & & & \\
Temperature & 7 & 6.8587 & $0.0007^{*}$ \\
Stage & 1 & 0.0236 & 0.8798 \\
Mate-pair[temperature] & 24 & 0.2243 & 0.9995 \\
Temperature $\times$ stage & 7 & 0.3497 & 0.9182 \\
ER & & & \\
Temperature & 7 & 12.8504 & $<0.0001^{*}$ \\
Stage & 1 & 0.2190 & 0.6476 \\
Mate-pair[temperature] & 24 & 1.6673 & 0.1694 \\
Temperature $\times$ Stage & 7 & 0.4658 & 0.8425 \\
\hline Significant at & & &
\end{tabular}

* Significant at the 0.05 level
(Table 3). However, the significance in stage at SC was solely driven by differences in expression at 13 and $21.1^{\circ} \mathrm{C}$. Variability due to mate-pair was not significant at any site (all $P>0.05$ ), and there were no interactions between factors at any site (all $P>0.05$; Table 3). Significant increases in expression above the site-specific controls occurred between 21 and $30^{\circ} \mathrm{C}$, with no significant variation in peak expression for each site. Thermal set-points for the initial temperature at which $h s p 70$ expression was significantly different from the control, $T_{\text {on }}$, and peak hsp70 expression, $T_{\max }$, are summarized in Table 4 . For the FC samples, the $T_{\text {on }}$ was $21.1^{\circ} \mathrm{C}$ for both developmental stages

Table 4 hsp70 expression thermal set-points

\begin{tabular}{llll}
\hline Site & Stage & $T_{\text {on }}\left({ }^{\circ} \mathrm{C}\right)$ & $T_{\max }\left({ }^{\circ} \mathrm{C}\right)$ \\
\hline FC & Gastrulae & 21.1 & 25 \\
& 4-arm plutei & 21.1 & 26.9 \\
SC & Gastrulae & 21.1 & $23.7-25.4$ \\
& 4-arm plutei & 21.1 & 25.4 \\
SB & Gastrulae & $21.8-23.4$ & $25-26.7$ \\
& 4-arm plutei & $21.8-23.4$ & $25-26.7$ \\
ER & Gastrulae & 21.8 & 25 \\
& 4-arm plutei & 21.8 & 25 \\
\hline
\end{tabular}

The initial temperature at which $h s p 70$ expression was significantly different from the control, $T_{\text {on }}$, and peak $h s p 70$ expression, $T_{\max }$ 
(Fig. 3). Peak $h s p 70$ expression $\left(T_{\max }\right)$ occurred at $25^{\circ} \mathrm{C}$ for gastrulae and $26.9^{\circ} \mathrm{C}$ for 4 -arm plutei; however, the differences in $T_{\max }$ were not significantly different (TukeyKramer HSD, $P=0.9958$; Fig. 3). In the SC samples, the $T_{\text {on }}$ occurred at $21.1^{\circ} \mathrm{C}$ for both stages and the $T_{\max }$ of hsp70 expression occurred between 23.7 and $25.4^{\circ} \mathrm{C}$ for gastrulae and $25.4^{\circ} \mathrm{C}$ for 4 -arm plutei; however, differences between the $T_{\max }$ were not significantly different (TukeyKramer HSD, $P=1.0$; Fig. 3). For the SB samples, the $T_{\text {on }}$ occurred between 21.8 and $23.4^{\circ} \mathrm{C}$, while the $T_{\max }$ occurred between 25 and $26.7^{\circ} \mathrm{C}$ for both gastrulae and 4-arm plutei (Fig. 3). Lastly, in the ER samples, $T_{\text {on }}$ occurred at $21.8^{\circ} \mathrm{C}$ and peak $h s p 70$ expression occurred at $25^{\circ} \mathrm{C}$ for both gastrulae and 4-arm plutei (Fig. 3). Due to a shift in the $\mathrm{Ct}$ expression values of the internal standard between sites, comparisons in the magnitude of $h s p 70$ expression between sites could not be confidently made.

Comparing the range between the absolute site-specific control temperature and $T_{\max }$, gastrulae and 4-arm plutei from $\mathrm{FC}$ had a range of $\sim 15^{\circ} \mathrm{C}, \mathrm{SC}$ had a range of $\sim 13^{\circ} \mathrm{C}$, and $\mathrm{SB}$ and $\mathrm{ER}$ both had a range of $10^{\circ} \mathrm{C}$ (Fig. 4). For simplicity, data were plotted from 4-arm plutei only as there were no significant differences between the two stages in $h s p 70$ expression profiles.

\section{Discussion}

The aim of this study was to compare the thermal tolerance of two early life history stages of $S$. purpuratus. Additionally, we sought to examine how the latitude at which the adult females went through oogenesis affected the hsp70 expression of the progeny. As the environmental characteristics encountered by the adults during oogenesis has the potential to affect offspring performance in most organisms (Mousseau and Fox 1998; Bacigalupe et al. 2007), including marine organisms (Li and Brawley 2004; Marshall 2008), for the present study embryos were obtained from adults that originated from various biogeographic locations throughout the recorded range of adult S. purpuratus (Morris et al. 1980; Tegner 2001) during the spawning season. Oogenesis in $S$. purpuratus typically occurs in autumn/winter (Gonor 1973; Pearse et al. 1986) when the temperatures range from an average of $\sim 12^{\circ} \mathrm{C}$ in central Oregon (National Data Buoy Center at NOAA; http://www.ndbc.noaa.gov/) to an average of $\sim 19^{\circ} \mathrm{C}$ near Ensenada, MX (Lluch-Cota et al. 2000). The salient findings of this study were as follows: (1) for thermal tolerance, measured as $\mathrm{LT}_{50} \mathrm{~s}$, there were no significant latitudinal trends, (2) for the two stages tested, there was no detectable difference in response for gastrulae and larvae, (3) using the expression of $h s p 70$ as a bioindicator of response to acute thermal stress, embryos and larvae displayed similar

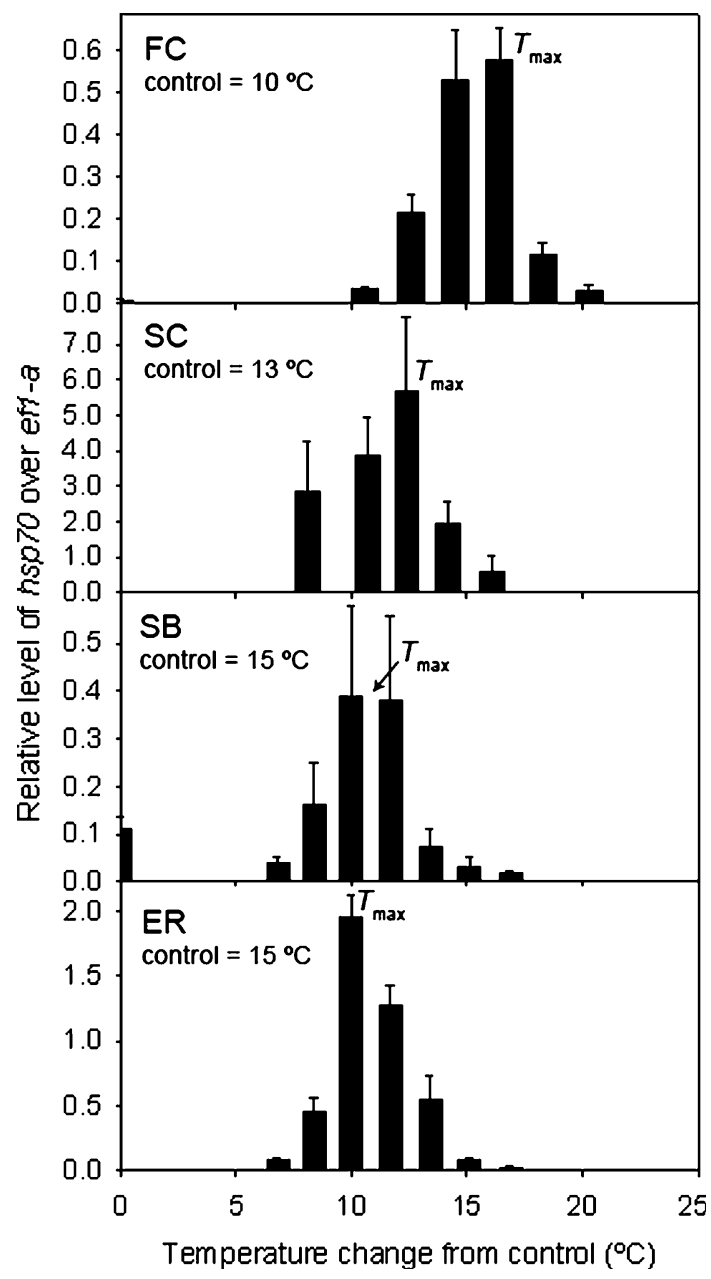

Fig. 4 Levels of $h s p 70$ mRNA expression in 4-arm plutei from each site relative to a common $S$. purpuratus larval standard and normalized to ef $1-\alpha$. Data were plotted from 4-arm plutei only as there were no significant differences between the gastrulae and 4-arm plutei in $h s p 70$ expression profiles. Values along the $x$-axis represent the change in heat exposure temperature from the control temperature used at each site

patterns of gene expression with no patterns detected across the latitudes at which adults were collected, and (4) there were subtle latitudinal trends in $h s p 70$ thermal set-points.

Overall, the results of this study suggest that different early developmental stages have similar whole-organism and molecular-level thermal tolerances across the range of purple urchins along the coast of the northeast Pacific.

Thermal tolerance of early life history stages: $\mathrm{LT}_{50} \mathrm{~S}$

In this study, we observed acute shifts in survivorship where mortality increased from near zero to $100 \%$ within a few degrees. Although, not always reflecting ecological average temperatures, these $\mathrm{LT}_{50}$ assays were employed in 
order to identify thresholds in tolerance, as has been done in numerous physiological studies (Stillman and Somero 2000; Somero 2002; Miller et al. 2009). Examinations of larval temperature tolerance have found similar abrupt increases in mortality (Brown et al. 2004; Kalosaka et al. 2009; Zippay and Hofmann 2010). For example, BoonNiermeijer and van de Scheur (1984) exposed Lymnaea stagnalis snail embryos and larvae to 1-h thermal challenges, and all stages studied experienced an abrupt increase in mortality between 39 and $40^{\circ} \mathrm{C}$. Sewell and Young (1999) observed abrupt decreases in survival in Echinometra lucunter urchin embryos and larvae exposed to 2-h thermal challenges; all stages experienced $100 \%$ survival until $38^{\circ} \mathrm{C}$ at which point mortality rapidly increased until $\sim 41^{\circ} \mathrm{C}$ when all stages exhibited $100 \%$ mortality. The acute shift in survivorship observed in this study suggests that the embryos and larvae may have reached the critical thermal threshold for the molecular mechanisms regulating thermal tolerance; this is discussed in more detail in the following section.

The mortality results between stages did not differ significantly at any of the sites. Additionally, the $\mathrm{LT}_{50} \mathrm{~S}$ and overall mortality profiles between stages were not significantly different, results that were similar to findings in embryos and larvae of the tropical sea urchin, Echinometra lucunter (Sewell and Young 1999). However, contrasting outcomes have been found in other species. Kalosaka et al. (2009) exposed 6 life history stages of the Mediterranean medfly, Ceratitis capitata, ranging from early embryos to adults to 1-h heat shocks at a range of temperatures and found different patterns of mortality based on life history stage. Sulkin and McKeen (1994) compared temperature-induced mortality in five zoeal stages between four congeneric Cancer crabs raised at 10,15 , and $20^{\circ} \mathrm{C}$ and found no clear pattern of mortality with temperature between the zoeal stages; different zoeal stages experienced different levels of mortality in all species investigated. The authors suggest that the differences in mortality may lead to dissimilar susceptibilities to thermal stress between developmental stages; however, it was not clear whether these unequal vulnerabilities were ecologically significant. In general, there appear to be no clear patterns in temperatureinduced mortality between early life history stages across species; mortality during early development appears to be species specific, and the present data further contributes to our understanding of intraspecific temperature tolerances between early developmental stages. For the S. purpuratus gastrulae and 4-arm plutei investigated here, the similarity in mortality profiles suggests that the likelihood of stage-specific mortality during early development, which may affect settlement and recruitment success, is minimized. hsp70 expression and developmental stage comparisons

Gastrulae and 4-arm plutei both upregulated $h s p 70$ similarly with no significant differences in expression, irrespective of the characteristic differences between these two life history stages. Gastrulae are swimming embryos that are in the process of forming the most basic structures (mouth, gut, and anus) while 4-arm plutei are feeding, swimming larvae with well-developed systems and defined structures (gastrointestinal system, early larval skeleton, etc.). Previous studies have shown that early urchin embryos do not display a heat-shock response before the gastrula stage (Sconzo et al. 1995; Giudice et al. 1999). This may, in part, be due to the fact that, for the embryo, much of the energy is expended on the proper formation of the germ layers and embryonic and larval structures. Because protein folding and molecular chaperone activities carry large energy requirements (Hochachka and Somero 2002) and because the over-expression of hsps can interfere with or inhibit development (Krebs and Feder 1998; Hamdoun and Epel 2007), the embryo would presumably put less energy toward mounting a defense response like the HSR and put more energy into further development than later, more developed stages. However, given the current data, this does not appear to be the case as once the embryo reached gastrula stage, it expressed $h s p 70$ at equal magnitudes as older, more developed plutei.

While the number of studies investigating stress-induced gene expression between early life history stages is few, the similarity in $h s p 70$ expression profiles between the two developmental stages studied here is similar to findings by previous studies investigating Hsp70 protein expression between early life history stages. When Botton et al. (2006) exposed Limulus polyphemus horseshoe crab embryos and larvae to a 3-h heat shock, both stages had Hsp70 protein present in relatively equal amounts. Additionally, BoonNiermeyer et al. (1988) found that when Lymnaea stagnalis snail gastrulae and trochophore larvae were exposed to temperature stress, both stages had similar relative values of Hsp70 protein. This suggests that particular stages in early development are similar in their capacity to initiate a HSR through the upregulation of $h s p 70$ and translation of Hsp70 protein. The similarity in expression potentially helps ensure that the embryonic and larval stages are equally equipped to withstand temperature stress until settlement and metamorphosis.

Biogeographic comparisons: macrophysiology, larval performance, and $h s p 70$

Measuring performance across large spatial scalesmacrophysiology (Gaston et al. 2009) — has been used to examine response to environmental temperature in a 
variety of marine invertebrates (e.g. Stillman and Somero 2000; Sorte and Hofmann 2004; Somero 2005). In this study, we measured mortality and $\mathrm{LT}_{50}$ temperatures as indices for thermal tolerance and found no clear latitudinal trend. The lack of a trend suggests $S$. purpuratus embryos and larvae have similar temperature tolerances at the whole-organism level throughout the species range. The number of studies comparing embryonic and larval thermal tolerances across latitude is few, and a similar study by Zippay and Hofmann (2010) on Nucella ostrina larvae, which develop in egg capsules attached to intertidal substrates, found contrasting results. In that study, Nucella ostrina egg capsules from across a large latitudinal range were collected and exposed to a range of thermal challenges in the laboratory and a strong latitudinal trend in $\mathrm{LT}_{50}$ temperatures was found. It is important to note, however, that the contrast in latitudinal trends between these studies may be a result of planktonic versus non-planktonic early life history stages as discussed below.

In this study, we also measured the expression of $h s p 70$, a common gene in the urchin defensome (Goldstone et al. 2006) that is rapidly upregulated in response to elevated temperature, and compared the expression in gastrulae and larvae across a large spatial scale. The $h s p 70$ expression profiles of both gastrulae and 4-arm plutei in this study did not differ between sites. The overall similarity in thermal setpoints (i.e., $T_{\text {on }}$ and $T_{\max }$ ) across sites found in this study contrasts with a similar study by Osovitz and Hofmann (2005) that found a latitudinal trend in thermal set-points in adult $S$. purpuratus, where southern individuals exhibited a $T_{\max }$ of $h s p 70$ expression at a higher temperature relative to northern individuals. Interestingly, studies that have found latitudinal trends in the HSR have done so predominately in adults where the shifts in thermal set-points highlighted local acclimatization along latitudinal or vertical habitat gradients and, thus, highlighted the plasticity in their thermotolerance (Tomanek and Somero 1999; Helmuth and Hofmann 2001; Sorte and Hofmann 2004; Osovitz and Hofmann 2005; Henkel and Hofmann 2008). Additionally, the organisms examined in these studies were predominately benthic or sessile with restricted ranges of movement, conditions under which local acclimatization is more likely to occur.

Planktonic early life history stages, on the other hand, are the dispersal stage and are less likely to have experienced set temperature regimes to which they could become acclimatized to, as they are not localized to any specific area until they settle. Under these circumstances, the lack of a latitudinal trend in this study may suggest that the upregulation of $h s p 70$ and, consequently, the HSR, is a genetically fixed response in $S$. purpuratus early life history stages. While the thermal set-points of the HSR have been shown to typically display variable yet significant plasticity (Barua and Heckathorn 2004), some exceptions have been found. Similar to the present study, adult Mytilus galloprovincialis mussels from across a large latitudinal gradient exhibited no significant variation in $T_{\max }$ after exposure to a 1-h thermal challenge, suggesting a fixed genetic response (Dutton and Hofmann 2009). Alternatively, the relatively identical $T_{\max }$ values across latitude found in this study may suggest that the early life history stages have a universal temperature tolerance as a mechanism to increase their likelihood of survival during the planktonic larval duration before settlement.

The similarity between gastrulae and 4-arm plutei in their mortality and $h s p 70$ expression profiles further reflects their similar timing of hsp gene activation and cessation, and their capacity for the HSR. Mortality did not begin to increase significantly until after $h s p 70$ expression reached the $T_{\max }$ value and began to cease. After the $T_{\max }$ was reached (approximately $25^{\circ} \mathrm{C}$ ), both gastrulae and 4-arm plutei likely exhibited failure of the HSR activation machinery. The HSR is controlled by transcriptional activation via heat-shock transcription factors (HSFs) and, although this regulatory step is known to be subject to some thermal acclimation (Buckley and Hofmann 2002; Buckley and Hofmann 2004), the process likely failed at approximately $25^{\circ} \mathrm{C}$ in both developmental stages, suggesting that the HSR transcriptional activation machinery is not only a fixed response but is not differentially regulated during different developmental stages. Subsequently, the embryos and larvae in this study reached their critical thermal thresholds at approximately $25^{\circ} \mathrm{C}$ and mortality increased rapidly, a pattern typical of the HSR (Tomanek and Somero 1999; Brown et al. 2004; Kalosaka et al. 2009).

Embryos and larvae of both SB and ER exhibited a smaller range of $h s p 70$ expression relative to the northern sites. The range of temperatures from the control temperature (which was equal to the temperature at which the adults were collected and therefore similar to conditions the embryos and larvae would have encountered in nature) to the temperature at which $h s p 70$ expression ceased was smaller in the southern sites $\left(15-32^{\circ} \mathrm{C}\right)$ than the range for the northern sites (FC: $10-31^{\circ} \mathrm{C}$; SC: $13-31^{\circ} \mathrm{C}$ ). More specifically, the range of expression between the site-specific control temperature and the $T_{\max }$ of $25^{\circ} \mathrm{C}$ at each site was smaller for southern individuals. These data suggest that the embryos and larvae from southern sites are closer to their upper thermal limits relative to northern individuals as there was no shift in the thermal set-points of the HSR. The narrower range in tolerance exhibited by the southern progeny would presumably make them more susceptible to increases in environmental temperatures, a similar conclusion drawn from other studies on marine ectotherms living close to their upper thermal limits (Stillman 2003; Tomanek 2008; Somero 2010). 


\section{Conclusion}

In measuring thermal tolerance and $h s p 70$ gene expression in two early life history stages of $S$. purpuratus, the results of this study show that gastrulae and 4-arm plutei respond similarly to thermal stress. Additionally, while the temperatures at which both gastrulae and 4-arm plutei began to express maximum $h s p 70$ expression and experienced significant mortality were higher than their average habitat temperature, these responses help characterize the upper thermal limits of the early life history stages and provide insight into how they may respond to temperature changes in surface waters where temperatures are typically significantly warmer and where the embryos and larvae are concentrated. Investigating how marine invertebrate larvae respond to thermal stress at the whole-organism and molecular levels will assist in predicting whether and how early life history stages are likely to adjust to environmental shifts in temperature.

Acknowledgments The authors would like to thank PISCO members from Oregon State University and Paul Tompkins (UCSC) for the collection of urchins, and Tim Crombie, Elizabeth Hoaglund and Dr. Sarah Lester for field assistance. We would also like to thank Drs. Steven Gaines, Bill Rice and Chris Osovitz for statistical advice. This research was funded by NSF grant (OCE-0425107) to GEH and by an NSF Graduate Research Fellowship to LMH.

Open Access This article is distributed under the terms of the Creative Commons Attribution Noncommercial License which permits any noncommercial use, distribution, and reproduction in any medium, provided the original author(s) and source are credited.

\section{References}

Adams NL, Shick JM (2001) Mycosporine-like amino acids prevent UVBinduced abnormalities during early development of the green sea urchin Strongylocentrotus droebachiensis. Mar Biol 138:267-280

Bacigalupe LD, Araya NM, Carter MJ, Catalana TP, Lardies MA, Bozinovic F (2007) Maternal effects, maternal body size and offspring energetics: a study in the common woodlouse Porcellio laevis. Comp Biochem Physiol A Mol Integr Physiol 147:349-354

Barua D, Heckathorn SA (2004) Acclimation of the temperature setpoints of the heat-shock response. J Therm Biol 29:185-193

Bédard PA, Brandhorst BP (1986) Translational activation of maternal messenger RNA encoding the heat-shock protein HSP90 during sea urchin embryogenesis. Dev Biol 117:286-293

Bingham BL, Bacigalupi M, Johnson LG (1997) Temperature adaptations of embryos from intertidal and subtidal sand dollars (Dendraster excentricus, Eschscholtz). Northwest Sci 71:108-114

Boon-Niermeijer EK, van de Scheur H (1984) Thermosensitivity during embryonic development of Lymnaea stagnalis (Mollusca). J Therm Biol 9:265-269

Boon-Niermeyer EK, Dewaal AM, Souren JEM, Vanwijk R (1988) Heat-induced changes in thermosensitivity and gene expression during development. Dev Growth Differ 30:705-715

Botton ML, Pogorzelska M, Smoral L, Shehata A, Hamilton MG (2006) Thermal biology of horseshoe crab embryos and larvae: a role for heat shock proteins. J Exp Mar Biol Ecol 336:65-73
Brown JH, Stevens GC, Kaufman DM (1996) The geographic range: size, shape, boundaries, and internal structure. Annu Rev Ecol Syst 27:597-623

Brown HM, Briden A, Stokell T, Griffin FJ, Cherr GN (2004) Thermotolerance and Hsp70 profiles in adult and embryonic California native oysters, Ostreola conchaphila (Carpenter, 1857). J Shellfish Res 23:135-141

Buckley BA, Hofmann GE (2002) Thermal acclimation changes DNA-binding activity of heat shock factor 1 (HSF1) in the goby Gillichthys mirabilis: implications for plasticity in the heatshock response in natural populations. J Exp Biol 205: 3231-3240

Buckley BA, Hofmann GE (2004) Magnitude and duration of thermal stress determine kinetics of hsp gene regulation in the goby Gillichthys mirabilis. Physiol Biochem Zool 77:570-581

Chown SL, Gaston KJ (2008) Macrophysiology for a changing world. Proc R Soc B Biol Sci 275:1469-1478

Derivera CE, Hitchcock NG, Teck SJ, Steves BP, Hines AH, Ruiz GM (2007) Larval development rate predicts range expansion of an introduced crab. Mar Biol 150:1275-1288

Doney SC, Fabry VJ, Feely RA, Kleypas JA (2009) Ocean acidification: the other $\mathrm{CO}_{2}$ problem. Annu Rev Mar Sci $1: 169-192$

Dutton JM, Hofmann GE (2009) Biogeographic variation in Mytilus galloprovincialis heat shock gene expression across the eastern Pacific range. J Exp Mar Biol Ecol 376:37-42

Edmunds PJ, Gates RD, Gleason DF (2001) The biology of larvae from the reef coral Porites astreoides, and their response to temperature disturbances. Mar Biol 139:981-989

Farmanfarmaian A, Giese AC (1963) Thermal tolerance and acclimation in the western purple sea urchin, Strongylocentrotus purpuratus. Physiol Zool 36:237-243

Fujisawa H (1989) Differences in temperature-dependence of early development of sea urchins with different growing seasons. Biol Bull 176:96-102

Fujisawa H, Shigei M (1990) Correlation of embryonic temperature sensitivity of sea urchins with spawning season. J Exp Mar Biol Ecol 136:123-140

Gaston KJ, Chown SL, Calosi P, Bernardo J, Bilton DT, Clarke A, Clusella-Trullas S, Ghalambor CK, Konarzewski M, Peck LS, Porter WP, Portner HO, Rezende EL, Schulte PM, Spicer JI, Stillman JH, Terblanche JS, van Kleunen M (2009) Macrophysiology: a conceptual reunification. Am Nat 174:595-612

Gaylord B, Gaines SD (2000) Temperature or transport? Range limits in marine species mediated solely by flow. Am Nat 155:769-789

Giudice G, Sconzo G, Roccheri MC (1999) Studies on heat shock proteins in sea urchin development. Dev Growth Differ 41:375-380

Goldstone JV, Hamdoun A, Cole BJ, Howard-Ashby M, Nebert DW, Scally M, Dean M, Epel D, Hahn ME, Stegeman JJ (2006) The chemical defensome: environmental sensing and response genes in the Strongylocentrotus purpuratus genome. Dev Biol 300:366-384

Gonor JJ (1973) Reproductive cycles in oregon populations of the echlnoid, Strongylocentrotus purpuratus (Stimpson). I. Annual gonad growth and ovarian gametogenic cycles. J Exp Mar Biol Ecol 12:45-64

Goto SG, Kimura MT (1998) Heat- and cold-shock responses and temperature adaptations in subtropical and temperate species of Drosophila. J Insect Physiol 44:1233-1239

Hamdoun A, Epel D (2007) Embryo stability and vulnerability in an always changing world. Proc Natl Acad Sci USA 104:1745-1750

Helmuth BST, Hofmann GE (2001) Microhabitats, thermal heterogeneity, and patterns of physiological stress in the rocky intertidal zone. Biol Bull 201:374-384

Henkel S, Hofmann G (2008) Differing patterns of hsp70 gene expression in invasive and native kelp species: evidence for acclimation-induced variation. J Appl Phycol 20:915-924 
Hochachka PW, Somero GN (2002) Biochemical adaptation: mechanism and process in physiological evolution. Columbia University Press, New York

Hofmann GE (2005) Patterns of Hsp gene expression in ectothermic marine organisms on small to large biogeographic scales. Integr Comp Biol 45:247-255

IPCC (2007) Climate change 2007: synthesis report contributions of working groups I, II and III to the fourth assessment report of the intergovernmental panel on climate change. IPCC Geneva, Switzerland

Johnson LG, Babcock RC (1994) Temperature and the larval ecology of the crown-of-thorns starfish, Acanthaster planci. Biol Bull 187:304-308

Kalosaka K, Soumaka E, Politis N, Mintzas AC (2009) Thermotolerance and HSP70 expression in the Mediterranean fruit fly Ceratitis capitata. J Insect Physiol 55:568-573

Krebs RA, Feder ME (1998) Hsp70 and larval thermotolerance in Drosophila melanogaster: how much is enough and when is more too much? J Insect Physiol 44:1091-1101

Leptin M (2005) Gastrulation movements: the logic and the nuts and bolts. Dev Cell 8:305-320

Li R, Brawley SH (2004) Improved survival under heat stress in intertidal embryos (Fucus spp.) simultaneously exposed to hypersalinity and the effect of parental thermal history. Mar Biol 144:205-213

Lindquist S (1986) The heat-shock response. Annu Rev Biochem 55:1151-1191

Lluch-Cota SE, Pacheco-Ayub CA, Bautista-Romero JJ, HernándezVázquez S, Lluch-Cota DB (2000) Colección de información ambiental para el Pacífico mexicano. CD-ROM CIBNOR, SC/ CONACYT

Marshall DJ (2008) Transgenerational plasticity in the sea: contextdependent maternal effects across the life history. Ecology $89: 418-427$

Miller LP, Harley CDG, Denny MW (2009) The role of temperature and desiccation stress in limiting the local-scale distribution of the owl limpet, Lottia gigantea. Funct Ecol 23:756-767

Morimoto RI (1998) Regulation of the heat shock transcriptional response: cross talk between a family of heat shock factors, molecular chaperones, and negative regulators. Genes Dev 12:3788-3796

Morris RH, Abbott DP, Haderlie EC (1980) Intertidal invertebrates of California. Stanford University Press, Stanford

Mousseau TA, Fox CW (1998) The adaptive significance of maternal effects. Trends Ecol Evol 13:403-407

Osovitz CJ, Hofmann GE (2005) Thermal history-dependent expression of the hsp70 gene in purple sea urchins: biogeographic patterns and the effect of temperature acclimation. J Exp Mar Biol Ecol 327:134-143

Pearse JS, Pearse VB, Davis KK (1986) Photoperiodic regulation of gametogenesis and growth in the sea urchin Strongylocentrotus purpuratus. J Exp Zool 237:107-118

Pörtner HO (2002) Climate variations and the physiological basis of temperature dependent biogeography: systemic to molecular hierarchy of thermal tolerance in animals. Comp Biochem Physiol A Mol Integr Physiol 132:739-761

Sagarin RD, Gaines SD (2002) Geographical abundance distributions of coastal invertebrates: using one-dimensional ranges to test biogeographic hypotheses. J Biogeogr 29:985-997

Sanford E, Holzman SB, Haney RA, Rand DM, Bertness MD (2006) Larval tolerance, gene flow, and the northern geographic range limit of fiddler crabs. Ecology 87:2882-2894

Sconzo G, Roccheri MC, La Rosa M, Oliva D, Abrignani A, Giudice G (1986) Acquisition of thermotolerance in sea-urchin
Paracentrotus lividus embryos correlates with the synthesis and age of the heat shock proteins. Cell Differ 19:173-178

Sconzo G, Ferraro MG, Amore G, Giudice G, Cascino D, Scardina G (1995) Activation by heat shock of HSP70 gene transcription in sea urchin embryos. Biochem Biophys Res Commun 217:1032-1038

Sconzo G, Amore G, Capra G, Giudice G, Cascino D, Ghersi G (1997) Identification and characterization of a constitutive HSP75 in sea urchin embryos. Biochem Biophys Res Commun 234:24-29

Sewell MA, Young CM (1999) Temperature limits to fertilization and early development in the tropical sea urchin Echinometra lucunter. J Exp Mar Biol Ecol 236:291-305

Somero GN (2002) Thermal physiology and vertical zonation of intertidal animals: optima, limits, and costs of living. Integr Comp Biol 42:780-789

Somero G (2005) Linking biogeography to physiology: evolutionary and acclimatory adjustments of thermal limits. Front Zool 2:1

Somero GN (2010) The physiology of climate change: how potentials for acclimatization and genetic adaptation will determine 'winners' and 'losers'. J Exp Biol 213:912-920

Sorte CJB, Hofmann GE (2004) Changes in latitudes, changes in aptitudes: Nucella canaliculata (Mollusca: Gastropoda) is more stressed at its range edge. Mar Ecol Prog Ser 274:263-268

Staver JM, Strathmann RR (2002) Evolution of fast development of planktonic embryos to early swimming. Biol Bull 203:58-69

Stillman JH (2003) Acclimation capacity underlies susceptibility to climate change. Science 301:65

Stillman JH, Somero GN (2000) A comparative analysis of the upper thermal tolerance limits of eastern Pacific porcelain crabs, genus Petrolisthes: influences of latitude, vertical zonation, acclimation, and phylogeny. Physiol Biochem Zool 73:200-208

Stillman JH, Tagmount A (2009) Seasonal and latitudinal acclimatization of cardiac transcriptome responses to thermal stress in porcelain crabs, Petrolisthes cinctipes. Mol Ecol 18:4206-4226

Strathmann R (1978) Length of the pelagic period in echinoderms with feeding larvae from Northeast Pacific. J Exp Mar Biol Ecol 34:23-27

Strathmann MF (1987) Reproduction and development of marine invertebrates of the Northern Pacific coast: data and methods for the study of eggs embryos and larvae. University of Washington Press, Seattle, pp XII + 670P

Sulkin SD, McKeen G (1994) Influence of temperature on larval development of 4 co-occurring species of the brachyuran genus Cancer. Mar Biol 118:593-600

Tegner MJ (2001) The ecology of Strongylocentrotus franciscanus and Strongylocentrotus purpuratus. In: Lawrence JM (ed) Edible sea urchins: biology and ecology. Elsevier, New York, pp 307-331

Tomanek L (2008) The importance of physiological limits in determining biogeographical range shifts due to global climate change: the heatshock response. Physiol Biochem Zool 81:709-717

Tomanek L, Somero GN (1999) Evolutionary and acclimationinduced variation in the heat-shock responses of congeneric marine snails (genus Tegula) from different thermal habitats: implications for limits of thermotolerance and biogeography. J Exp Biol 202:2925-2936

Wolpert L (1992) Gastrulation and the evolution of development. Development 116:7-13

Zacherl D, Gaines SD, Lonhart SI (2003) The limits to biogeographical distributions: insights from the northward range extension of the marine snail, Kelletia kelletii (Forbes, 1852). J Biogeogr 30:913-924

Zippay ML, Hofmann GE (2010) Physiological tolerances across latitudes: thermal sensitivity of larval marine snails (Nucella spp.). Mar Biol 157:707-714 